University of South Carolina

Scholar Commons

Faculty Publications

Sociology, Department of

Spring 2001

\title{
SOCIAL INFLUENCE ON PARANORMAL BELIEFS
}

Barry N. Markovsky

University of South Carolina - Columbia, barry@sc.edu

Shane R. Thye

University of South Carolina - Columbia, srthye@sc.edu

Follow this and additional works at: https://scholarcommons.sc.edu/socy_facpub

Part of the Sociology Commons

\section{Publication Info}

Sociological Perspectives, Volume 44, Issue 1, Spring 2001, pages 21-44.

This Article is brought to you by the Sociology, Department of at Scholar Commons. It has been accepted for inclusion in Faculty Publications by an authorized administrator of Scholar Commons. For more information, please contact digres@mailbox.sc.edu. 


\title{
SOCIAL INFLUENCE ON PARANORMAL BELIEFS
}

\author{
BARRY MARKOVSKY* \\ University of Iowa \\ SHANE R. THYE \\ University of South Carolina
}

\begin{abstract}
In spite of strong public expressions of skepticism from the scientific community, polls show that more than nine out of ten American adults profess belief in paranormal phenomena. Some scientists view this as a social problem, directing much blame (but little research) at a variety of sources including lack of critical thinking skills, fads, need for transcendent experiences, failure of the educational system, and cultural cycles. Social impact theory provides an alternative focus: it views paranormal beliefs as a natural consequence of social influence processes in interpersonal settings. In this study, subjects in a laboratory experiment were informed that some people believe pyramids harness a mysterious form of energy that preserves objects stored within them. They subsequently judged the relative freshness of fruit stored in a box and in a pyramid-shaped container. Although the judged stimuli essentially were identical, we observed that (1) subjects reported more "pyramid power" effects after hearing the credulous judgments of a confederate posing as a subject; (2) influence was heightened by a high-status confederate; (3) influence scarcely diminished when a prior subject's (i.e., an absent confederate's) judgments were reported to the subject by the experimenter; and (4) removing paranormal implications heightened the confederate's impact. To our knowledge, this is the first experimental demonstration of the interpersonal transmission of paranormal beliefs and the first time that all three of social impact theory's "source" factors-strength, immediacy, and number-have been tested in a single controlled experimental setting.
\end{abstract}

National surveys find broad public support for all manner of paranormal, supernatural, and occult beliefs. More than 90 percent of American adults profess at least one such belief, and the rates for some beliefs have risen steeply in recent years (Gallup 1979, 1997; Gallup and Newport 1990; McAneny 1995). ${ }^{1}$ Although every historical epoch has seen its share of legitimate scientific mysteries and anomalies, the great majority of paranormal claims either are consistent with

*Direct all correspondence to: Barry Markovsky, Department of Sociology, University of Iowa, Iowa City, IA 52242; e-mail: barry-markovsky@uiowa.edu. 
more prosaic explanations unknown to the claimants and observers or unravel completely in cases where systematic investigation is conducted. Nevertheless, the reason that many alleged scientific anomalies- "Bigfoot," reincarnation, alien abductions, telepathy, faith healing, and so on-are so tantalizing is because they fly in the face of laws or precedents that most presume hold in practically all other places and times. ${ }^{2}$

Influential writers from across the academic spectrum suspect that paranormal beliefs are symptomatic of more fundamental and potentially harmful lapses in perceptual capacities, critical thinking abilities, evidential reasoning, and, more generally, the educational system (e.g., Friedlander 1995; Gilovich 1991; Kurtz 1991; Paulos 1988, 1991; Sagan 1995; Shermer 1997). They cite cases of cults whose members fail to see through powerful recruitment and thought control techniques, with promises of supernormal powers and enlightenment (Hassan 1988; Miller 1987; Singer 1995); families split by the uncritical acceptance of therapistinduced false memories of abuse and molestation (Baker 1992; Spanos 1996); and the widespread popularity of faith healers and practitioners of dubious healing arts who sometimes harm patients directly with their untested remedies, or indirectly by dissuading clients from more appropriate treatments (Barrett and Jarvis 1993; Buckman and Sabbagh 1995; Randi 1987).

The New Age movement has spawned a vast market for seminars, products, and publications, most based on questionable claims (Gardner 1991; Stenger 1990). The judicial system has proven ill-equipped to sift the valid from the false, often with costly and unjust results (Huber 1991). A highly visible contingent of celebrities can be seen on talk shows and "infomercials" endorsing their favorite psychics. Even government leaders have admitted involvement: President and Mrs. Ronald Reagan employed the services of astrologers to assist them in making important decisions that affected the nation (Gardner 1992). More recently, President and Mrs. Bill Clinton were counseled by prominent psychics and New Age gurus (Woodward 1996). Even if such highly conspicuous endorsements do not influence the public directly, at the very least they set a tone that embraces and legitimizes paranormal solutions to life's problems, however small or large.

The etiology of paranormal beliefs is multidimensional and multilevel, and so it is appropriate for researchers to seek diverse causes at different levels of analysis. In the social and behavioral sciences, efforts to determine the nature and sources of paranormal beliefs have taken two general directions. One leans toward the psychological, emphasizing sensory, perceptual, cognitive, and experiential processes (Alcock 1980; Blackmore 1991, 1993; Gilovich 1991; Nisbett and Ross 1980; Reed 1988; Zusne and Jones 1982). For example, Vyse's Believing in Magic (1997) explicitly takes an individualistic perspective on the nature and sources of superstitious and paranormal beliefs. Vyse recognizes that social factors may condition these beliefs but that such considerations fall under the purview of other disciplines. The other approach seeks to identify cultural, demographic, religious, and other variables that correlate with paranormal beliefs, typically as they are expressed on survey instruments (Gallup and Newport 1990; Greely 1975; Harrold and Eve 1987a; MacDonald 1994; McClenon 1994). This is the direction usually taken by sociologists, although Goode's (2000) text is exceptional for its 
coverage of multiple perspectives and numerous case reviews. Missing from these two research directions is a meso-level: social influences operating in interpersonal or small group contexts. These stand in contrast to the "micro" factors of cognition and information processing and the "macro" interests in cultural, institutional, and social structural processes.

This is not to say that previous work denies the existence or importance of proximal, interpersonal or group influences on paranormal beliefs. If anything, the opposite is true: such influences generally are taken for granted by paranormal belief researchers (e.g., Pratkanis 1995). However, social influence theories imply that the interpersonal transmission of a paranormal belief is far from automatic. Here we begin to consider such effects by systematically testing one theory of interpersonal influence.

\section{SOCIAL INFLUENCE AND SOCIAL IMPACT}

It is axiomatic that those who are socially proximate directly and indirectly influence one another's actions, attitudes, and beliefs (Erickson 1988; Friedkin 1991, 1993; Latané et al. 1995; Rogers 1983). ${ }^{3}$ It also is well established that beliefs spread in contexts highly conducive to persuasion, as when there are esteemed "sources," curious "targets," cogent and well-tailored arguments, and engaging media (O'Keefe 1990; Petty and Cacioppo 1986; Pratkanis and Aronson 1992). Still, however, social bonds and persuasion may not account for the diversity, ubiquity, and broader social patterning of paranormal beliefs revealed in attitude surveys and opinion polls (Davis and Smith 1991; Gallup and Newport 1990; Greely 1975; McAneny 1995; Tobacyk et al. 1988). These considerations-along with the theory we present below-led us to ask four specific questions, each with a range of broader ramifications: (1) Can paranormal beliefs be transmitted to one person by mere exposure to a credulous source, even in nonpersuasive contexts? (2) Are such beliefs transmitted as readily as others that are devoid of paranormal connotations? (3) Are higher-status sources more influential? (4) Are proximate sources more influential? Affirmative answers to these questions would establish a mechanism for highly contagious, widespread, socially patterned beliefs in the paranormal-a mechanism that is grounded in basic social influence processes and that does not rely on elaborate presuppositions about individual characteristics such as credulity or persuadability.

For mere exposure to be sufficient for paranormal beliefs to spread, a passive social influence process must transpire, a process that is patterned by preexisting social networks and by the consumer demographics for radio and television programs, movies, books, magazines, and newspapers. That the popular media are overwhelmingly supportive of paranormal claims facilitates their dissemination and hinders critical evaluation (Klare 1990; Nollinger 1994; Sparks 1998; Sparks and Pellechia 1997; Sparks, Nelson, and Campbell 1997; Sparks, Sparks, and Gray 1995). Although we do not track this process in its entirety, a crucial point must be the moment at which one is confronted with an ostensibly paranormal claim or circumstance and has the opportunity and motivation to evaluate it. Our basic tenet is that the acceptance or rejection of the claim is conditioned by social factors 
and not solely by its internal logic, the quality of evidence supporting it, the degree to which mundane explanations have been ruled out, or the target's personality characteristics and preexisting belief systems. Here we use controlled laboratory tests to understand the basic mechanisms through which social factors operate.

Although once the dominant project of social psychology, general theories of social influence no longer cut such a wide swath through the journals of the field. Social impact theory may be the exception. Developed and tested by Latané and his colleagues, this theory is expanding on several fronts, and research continues to be conducted and published in prominent journals (Latané 1981; Latané et al. 1995; Latané and L'Herrou 1996; Latané and Wolf 1981; Nowak, Szamrej, and Latané 1990). Social impact refers to "any of the great variety of changes in physiological states and subjective feelings, motives and emotions, cognitions and beliefs, values and behavior, that occur in an individual, human or animal, as a result of the real, implied, or imagined presence or actions of other individuals" (Latané 1981:343). The social impact of a message source on a person is assumed to be a positive multiplicative function of three factors: the number of others constituting the source; their strength, that is, "salience, power, importance, or intensity, . . . status ... [or existence of a] prior relationship" (p. 344); and their immediacy, that is, their "closeness in space or time and absence of intervening barriers or filters" (p. 344). ${ }^{4}$ Such effects are diminished by impediments, such as a nonlegitimate information source or an incredulous target. The theory encompasses a range of findings in the areas of conformity, imitation, obedience, persuasion, and compliance and also generates its own unique predictions. ${ }^{5}$

More recently, dynamic social impact theory specifies mechanisms for the diffusion of beliefs through social systems (Latané and L'Herrou 1996; Nowak, Szamrej, and Latané 1990; Nowak and Vallacher 1998). Once influenced by others, an actor's altered beliefs will contribute to belief change among those to whom she or he has strong, immediate social ties. In this way, beliefs may travel through a social system via communication networks (ranging from informal conversation to transmissions via broadcast media) and become self-sustaining as members of a "critical mass" of believers reinforce one another's positions. The image also is consistent with Dawkins's (1989) "meme theory." By this view, certain replicable entities, such as the idea of astrological forces, are capable of propagating through populations of carriers. They accomplish this by virtue of possessing a particular constellation of properties that happens to resonate with members. The result, in the context of dynamic social impact theory, is that numerous members of a social system come to accept a belief, while some pockets of strong believers resist change- a condition that reflects patterns of paranormal beliefs such as those we noted earlier. For social impact theory to work "in the large," however, first it must work "in the small." In this case, dynamic models of social impact would suggest that widespread belief in the paranormal will emerge only when conditions are ripe for micro-level influence. In our research we consider (1) if the paranormality of a claim facilitates this process; and if so (2) do the assumptions of social impact theory adequately describe how such claims are transmitted from person to person. To answer these questions we test social impact theory by 
manipulating all three of its causal factors. No previous test has incorporated all of social impact theory's source factors, and impediments to impact, in the same experimental setting. In addition, to our knowledge, this is the first time that interpersonal influences on paranormal beliefs have been demonstrated experimentally.

\section{PYRAMID POWER}

"Pyramidology" has long been characterized by pseudoscientific numerological excursions (Gardner 1957:chap. 15). Since the mid-twentieth century a wave of popularized claims has endowed pyramids with a mysterious energetic force. Public belief in "pyramid power" rose dramatically in the 1960s and 1970s and surged again in the 1980s and early 1990s with the emergence of the New Age movement. Most Americans probably are aware that special powers are attributed to pyramids, but the specifics have not been broadly popularized, and few people are likely to have strong beliefs one way or the other. This makes it a propitious claim for our use.

Among the many powers attributed to pyramids are preservative and restorative effects on objects stored beneath or within them (Cazeau 1986; Daniels and Horan 1987; Ostrander and Schroeder 1970; Stine 1992; Toth 1974). Most accounts assert that pyramids focus some type of "energy" on objects stored inside them but tend to rely heavily on speculation and only lightly on evidence (e.g., Stine 1992). Among the claims are that a pyramid will preserve organic materials, sharpen razor blades, and cure illness.

As far as we know, no systematic double-blind test of pyramid power claims has ever been published. Before investigating social impact, we thought it a worthwhile exercise to conduct such a test. Results indicated that the pyramid had no detectable effect (Thye and Markovsky 1994). ${ }^{6}$ The experiment that we report below, in contrast, was designed to determine if a relatively weak manipulationthe mere presence of another who reports perceiving a pyramid effect-is sufficient to induce subjects also to report an effect and to internalize the belief that the effect was real.

\section{METHOD}

The research and results are organized below in terms of the four questions posed earlier. Each involves a contrast between a common baseline condition and another condition in which a specific factor is manipulated. Taken together, these five conditions address the four questions motivating our study. First we review the procedures common to all conditions.

\section{Procedures in Common}

The experiment was conducted at the University of Iowa. Subjects registered in classes to participate in research projects and were scheduled by a project assistant. The pyramid, not much larger than a shoebox, was constructed to within a 1 percent tolerance of published specifications (Watson 1973). The pyramid and a 


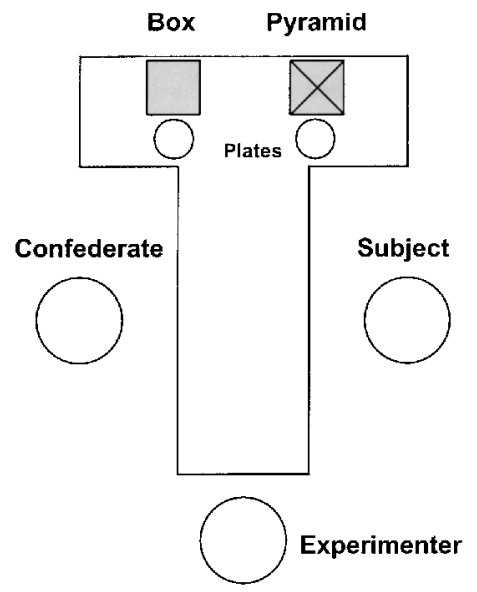

Figure 1

Experiment Room Arrangement

box of equal volume were placed at the horizontal end of a T-shaped table (Figure 1). ${ }^{7}$ The experimenter sat at the bottom of the $T$, with the subject on one side of the vertical section. When present, the confederate sat opposite the subject.

Before the start of a session, subjects completed a Background Information Form and a twenty-item Paranormal Beliefs Questionnaire designed to measure beliefs in a variety of paranormal and pseudoscientific claims, and whether close friends hold similar beliefs (see the Appendix). ${ }^{8}$ A broad selection of claims was included on the questionnaire, based on items that have demonstrated desirable qualities in previous research (e.g., Tobacyk and Milford 1983). The experimenter gave oral instructions that included a brief review of "evidence" for the pyramid's special powers, such as the fact that the bodies of pharaohs entombed in the Egyptian pyramids are so well preserved. Subjects also were told, "Last week we selected two equally fresh bananas. One was placed under a pyramid, the other under a box. I'll be showing you these bananas and asking you to rate them on five different characteristics."

The pairs of bananas used in all conditions were virtually identical, selected on the basis of similarity ratings of five or more judges. Before the start of every session, the experimenter assigned the bananas to the two containers so as to reverse the placement used for the previous subject. This counterbalancing procedure ensured that results could not be biased by any natural differences that may have emerged over the several days each set of bananas was used.

When present, the confederate posed as a second subject. During the judgment sequences, confederates did not attempt to influence or interact with subjects, and no incentives were provided for the subject to either agree or disagree with the confederate's ratings. With the exception of one condition described below, confederates closely matched subjects in terms of age, sex, and education.

Subjects provided oral ratings for both bananas on five fifteen-point bipolar 
semantic differential scales. Each subject rated the same banana first (either the pyramid-covered or box-covered banana) on all five scales, and the order of the two bananas (box first vs. pyramid first) was counterbalanced across experimental sessions. Pretests determined the three most discriminating scales (PreservedUnpreserved, Fresh-Rotten, and Hard-Soft), and these were assigned randomly to the first, third, and fifth positions in the sequence. The other two scales (LightDark, New-Old) appeared second and fourth, their sequence reversed half the time. When a confederate was present, he or she alternated on each oral rating. The confederate was always queried before the subject on ratings 1, 3, and 5, and after the subject on 2 and 4 . The experimenter made it appear that the choice to begin with the confederate on the first trial was spontaneous and arbitrary. The confederate's responses for each scale were predetermined and chosen to indicate that she or he perceived the pyramid banana to be considerably fresher than the box banana, always rating the pyramid banana as fresher by either four or five points on the fifteen-point scale.

Social influence researchers have long known that public and private ratings do not necessarily coincide (Asch 1956; Sherif 1935). To allow subjects to express their beliefs regarding the pyramid's effect without having to feel accountable to a confederate or an experimenter, we had them complete their final ratings alone. The private rating scales differed in number (four) and appearance from those in the oral ratings to help minimize any "response set" bias. The left end-anchor $(-7)$ indicated the belief that the pyramid has a much greater preservative effect than the box; the center point ( 0$)$ indicated no difference; and the right end-anchor $(+7)$ indicated a greater preservative effect for the box.

\section{Question 1: “Can Paranormal Beliefs be Transmitted?"}

Earlier we asked, Can paranormal beliefs be transmitted to one person by mere exposure to a credulous other person, even in nonpersuasive contexts? Social impact theory predicts that the addition of the first source has the strongest marginal effect on a lone actor (Latané 1981). ${ }^{9}$ Therefore, it is critical to determine whether one confederate induces a measurable social impact in our experimental setting.

\section{Design}

Question 1 can be answered by contrasting two conditions: "confederate" (Condition 1) and "no confederate" (Condition 2). The operative difference is that in Condition 2, where no confederate is present, the subject does not hear another's ratings before giving his or her own.

\section{Hypotheses}

Social impact theory predicts that if the source's expressed belief diverges from the target's, then in the absence of impediments, the target's beliefs and behaviors will shift in the direction of the source's. Thus, when a confederate states that one of the bananas appears fresher, the subject's judgment should move toward the 
confederate's. If our experimental setting generates social impact, then the pyramid bananas should be rated fresher in Condition 1 than in Condition 2.

\section{Results $^{10}$}

Factor analysis revealed three distinct dimensions in the Paranormal Beliefs Questionnaire. Six items forming one factor were summed to create a paranormal beliefs subscale (items 1, 3, 6-9; Cronbach's $\alpha=.83$ ); seven items formed a subscale for friends' paranormal beliefs (items 14-20; $\alpha=.84$ ); and one item (13) stood alone as a third factor: belief in pyramid power. The key dependent variable in our analysis captures within-subject differences between the ratings of the two bananas. The difference score (D) aggregates binary influence measures: +1 on trials where influence is indicated (pyramid banana rated fresher than box banana), and 0 otherwise. D is then calculated as the sum of the scores across the three critical trials. This difference score is a simple indicator of influence/noninfluence, sensitive to whether or not subjects' judgments are consistently influenced by those of the confederate. For comparison purposes, we constructed a second index by subtracting each subject's pyramid rating from his or her own box rating for each trial and summing across the three critical trials. Our second difference score captures information on magnitudes, that is, the degree to which the two judgments on a given trial are differentiated. All analyses were conducted for both indices, and the two yielded very similar results. Thus we report statistics for only the simpler index.

In any experiment, uncontrolled factors can increase variability in the dependent measure and diminish the experiment's efficacy. When researchers suspect that certain factors may correlate with the dependent variable, measures may be obtained for them and statistical controls can be used to supplement experimental controls. Theory and previous research suggest that educational experiences, prior paranormal beliefs, and beliefs of others in one's social network may correlate with one's tendency to express paranormal beliefs (Bainbridge 1978; Blackmore and Troscianko 1985; Gray 1985; Harrold and Eve 1987b; Otis and Alcock 1982; Wierzbicki 1985). Therefore, we obtained data on several prior beliefs and demographic variables. Subjects were assigned to conditions randomly, and we verified that individual attributes are not correlated with the conditions of our experiment. Partitioning off the variation in D that is attributable to such factors should allow any true effects of the experimental manipulations to emerge more clearly, as well as specify more accurately the statistical model. Preliminary analyses indicated that several of the covariates had a consistent effect across all conditions and experiments. When not statistically controlled, these factors can act as suppressor variables (Babbie 1989), partially masking the effects of experimentally manipulated factors.

Covariates that were consistently significant in our analyses are reported below. However, the paranormal beliefs subscale was not a significant covariate in any tests, so this factor is excluded in the results reported below. ${ }^{11}$ Table 1, Panel A, displays the means and standard deviations for the conditions relevant to the first tests. Panel B shows the analysis of covariance (ANCOVA) for the effects of conditions and covariates. ${ }^{12}$ The hypothesis is supported: The pyramid banana was rated significantly fresher in the confederate condition. 
TABLE 1

Analyses of Covariance, Condition 1 versus Condition 2

A) Oral and Private Ratings, Means and Standard Deviations

\begin{tabular}{lcccc} 
Condition & Description & Oral & Private & \\
\hline 1 & Confederate & D Score & 1.780 & Ratings \\
& & 1.561 & $(3.857)$ & 41 \\
2 & No confederate & $(1.285)$ & 0.304 & 23
\end{tabular}

B) Oral Ratings

\begin{tabular}{lrrrrr} 
Source & \multicolumn{1}{c}{$S S$} & $d f$ & \multicolumn{1}{c}{ MS } & \multicolumn{1}{c}{$F$} & $p$ \\
\hline Condition $(1,2)$ & 9.592 & 1 & 9.592 & 8.498 & .005 \\
Year in school & 11.825 & 1 & 11.825 & 10.476 & .002 \\
Pyramid power belief & 14.765 & 1 & 14.765 & 13.081 & .001 \\
Friends' beliefs & 8.807 & 1 & 8.807 & 7.803 & .007 \\
Error & 66.594 & 59 & 1.129 & &
\end{tabular}

C) Private Ratings

\begin{tabular}{lrrrrr} 
Source & \multicolumn{1}{c}{$S S$} & $d f$ & $M S$ & $F$ & $p$ \\
\hline Condition $(1,2)$ & 48.853 & 1 & 48.853 & 4.638 & .035 \\
Year in school & 80.149 & 1 & 80.149 & 7.610 & .008 \\
Pyramid power belief & 58.759 & 1 & 58.759 & 5.579 & .021 \\
Friends' beliefs & 6.990 & 1 & 6.990 & 0.664 & .419 \\
Error & 621.414 & 59 & 10.532 & & \\
\hline
\end{tabular}

For the private ratings, factor analysis revealed that four questionnaire items loaded reasonably well on a single factor and correlated with oral ratings $(r=$ .721). For the sake of consistency, we combined the three scales that corresponded to the three qualities measured in the oral ratings-freshness, hardness, and preservation. We summed each subject's responses on these three items to create a single private rating scale $(\alpha=.882)$. The ANCOVA for private ratings appears in Panel C of Table 1 . The effect of the confederate on private ratings was statistically significant. ${ }^{13}$ The only notable distinction between the ANCOVAs for the oral and private ratings was the lack of a significant effect of friends' beliefs on private ratings.

In sum, the hypotheses received strong support: The confederate influenced the subjects' judgments to a significant degree, and private responses to postexperiment questionnaires indicated that the influence was internalized as a belief. ${ }^{14}$

\section{Question 2: "Is There a Unique Impact of the Paranormal Context?"}

Above we asked whether paranormal beliefs are transmitted as readily as others that are devoid of paranormal connotations. We reasoned that the paranormal 
overtones implicit in the confederate's expressed judgment may operate as an "impediment" to social impact, to use Latané's term. That is, compared to the case of a more socially accepted kind of claim, influence may be impeded for subjects who perceive a claim to be less legitimate.

\section{Design}

The second question was addressed by contrasting two conditions: "paranormal context" (Condition 1) and "normal context" (Condition 3). In Condition 3, the pyramid was replaced by a plastic container very close in size and shape to the cardboard box, and references to pyramids in the instructions were eliminated. Subjects were instructed that they would judge the effects of different containers on organic material. Analogous to the information on pyramid power given in Condition 1, subjects in Condition 3 were told that some people believe plastic boxes are more preservative than cardboard, with brief supportive arguments provided. Thus, both conditions had subjects consider a claim that was corroborated by a confederate-a paranormal claim in Condition 1 and a normal claim in Condition 3.

\section{Hypothesis}

We hypothesize that, because paranormal claims generally are viewed as less legitimate than nonparanormal claims, the paranormal context will impede social impact. Therefore, influence in Condition 3 should exceed that in Condition 1. Where influence occurs, subjects should internalize their judgments and manifest influence in their private ratings.

\section{Results}

Table 2 is organized the same way as Table 1: means and standard deviations in Panel A, the ANCOVA on oral ratings difference scores in Panel B, and the ANCOVA for private ratings in Panel C. Effects for conditions and the covariates are all significant. This provides clear support for the hypothesis that social impact in the context of the nonparanormal issue exceeds that in the paranormal context. The strong, significant effect for the private ratings indicates that there was greater internalization when the claim was without paranormal connotations. In sum, the contrast between Conditions 1 and 3 demonstrates that, even while social influence occurred to a significant degree in Condition 1, the paranormal context appears to have operated as an impediment to that influence. Even greater influence occurred when paranormal implications were removed.

\section{Question 3: "Is There a Status Effect?"}

Earlier we posed the question, Are paranormal beliefs transmitted more readily by higher-status others? Condition 4 introduced a high-status confederate, con- 
TABLE 2

Analyses of Covariance, Condition 1 versus Condition 3

A) Oral and Private Ratings, Means and Standard Deviations

\begin{tabular}{lcccc} 
Condition & Description & Oral & Private & N Score \\
\hline 1 & Confederate & 1.561 & 1.780 & 41 \\
& & $(1.285)$ & $(3.857)$ & \\
3 & No pyramid & 2.075 & 3.175 & 40
\end{tabular}

B) Oral Ratings

\begin{tabular}{lrrrrr} 
Source & \multicolumn{1}{c}{$S S$} & $d f$ & \multicolumn{1}{c}{ MS } & \multicolumn{1}{c}{$F$} & $p$ \\
\hline Condition $(1,3)$ & 12.196 & 1 & 12.196 & 9.003 & .004 \\
Year in school & 14.756 & 1 & 14.756 & 10.893 & .001 \\
Pyramid power belief & 5.534 & 1 & 5.534 & 4.085 & .047 \\
Friends' beliefs & 5.589 & 1 & 5.589 & 4.126 & .046 \\
Error & 102.947 & 76 & 1.129 & &
\end{tabular}

C) Private Ratings

\begin{tabular}{lrrrrr} 
Source & \multicolumn{1}{c}{$S S$} & $d f$ & $M S$ & \multicolumn{1}{c}{$F$} & $p$ \\
\hline Condition $(1,3)$ & 109.485 & 1 & 109.485 & 8.361 & .005 \\
Year in school & 165.877 & 1 & 165.887 & 12.667 & .001 \\
Pyramid power belief & 64.264 & 1 & 64.264 & 4.907 & .030 \\
Friends' beliefs & 15.579 & 1 & 15.579 & 1.190 & .279 \\
Error & 995.255 & 76 & 13.095 & & \\
\hline
\end{tabular}

trasting with the equal-status confederate in Condition 1. Latané (1981:344) explicitly cites status as an exemplar of the strength factor in his theory. Although status effects have been studied extensively in collective task situations (e.g., Balkwell 1994; Wagner and Berger 1993), we are unaware of its inclusion in previous tests of social impact theory or in any research on paranormal beliefs.

\section{Design}

We tested for the status effect by contrasting the influence of an equal-status confederate (Condition 1) with that of a high-status confederate (Condition 4). The high-status confederate was a thirty-nine-year-old male identified as a professor at the university where the study was conducted. The confederate responded to several questions by the experimenter in the subject's presence, making it obvious that his occupational status, age, and education exceeded that of the subject. To avoid raising suspicion, he added that he was curious about the research and signed up to participate when a project assistant recruited students from a course he taught. 
TABLE 3

Analyses of Covariance, Condition 1 versus Condition 4

A) Oral and Private Ratings, Means and Standard Deviations

\begin{tabular}{lcccc} 
Condition & Oral & Private & \\
Ratings & D Score & 1.780 & 41 \\
\hline \multirow{2}{*}{4} & Confederate & 1.561 & $(3.857)$ & \\
& & $(1.285)$ & 2.625 & 40 \\
& High status & 2.125 & $(3.677)$ &
\end{tabular}

B) Oral Ratings

\begin{tabular}{|c|c|c|c|c|c|}
\hline Source & SS & $d f$ & MS & $F$ & $p$ \\
\hline Condition $(1,4)$ & 4.345 & 1 & 4.345 & 4.159 & .045 \\
\hline Year in school & 18.985 & 1 & 18.985 & 18.170 & .000 \\
\hline Pyramid power belief & 17.983 & 1 & 17.983 & 17.211 & .000 \\
\hline Friends' beliefs & 5.135 & 1 & 5.135 & 4.914 & .030 \\
\hline Error & 79.410 & 76 & 1.045 & & \\
\hline
\end{tabular}

C) Private Ratings

\begin{tabular}{lrrrrr} 
Source & \multicolumn{1}{c}{$S S$} & $d f$ & \multicolumn{1}{c}{$M S$} & \multicolumn{1}{c}{$F$} & $p$ \\
\hline Condition $(1,4)$ & 24.688 & 1 & 24.688 & 1.375 & .245 \\
Year in school & 319.825 & 1 & 319.825 & 17.817 & .000 \\
Pyramid power belief & 202.557 & 1 & 202.557 & 11.284 & .001 \\
Friends' beliefs & 21.359 & 1 & 21.359 & 1.190 & .279 \\
Error & 1364.228 & 76 & 17.950 & & \\
\hline
\end{tabular}

\section{Hypothesis}

Because status is assumed to operate as a strength factor, we should observe a greater degree of influence in the high-status condition than in the equal-status condition. The effect is also predicted to carry through to the private ratings.

\section{Results}

Results and analyses pertinent to the strength factor are given in Table 3 . The effect of the high-status confederate on oral ratings (Panel B) was statistically significant. Panel C of Table 4, however, shows there not to have been a significant effect for the private ratings. We will return to this negative finding below in the Discussion section.

\section{Question 4: "Is There an Immediacy Effect?"}

Are proximate sources of paranormal beliefs the most influential? Our final contrast examined the effect of the confederate's immediacy — "closeness in space 
TABLE 4

Analyses of Covariance, Condition 1 versus Condition 5

A) Oral and Private Ratings, Means and Standard Deviations

\begin{tabular}{lcccc} 
Condition & Description & Oral & Private \\
Ratings & $N$ \\
\hline 1 & Confederate & 1.561 & 1.780 & 41 \\
& & $(1.285)$ & $(3.857)$ & \\
& & 1.366 & 1.171 & 41 \\
& Absent & $(1.199)$ & $(3.721)$ &
\end{tabular}

B) Oral Ratings

\begin{tabular}{lrrrrc} 
Source & \multicolumn{1}{c}{$S S$} & $d f$ & $M S$ & $F$ & $p$ \\
\hline Condition $(1,5)$ & 0.626 & 1 & 0.626 & 0.438 & .510 \\
Year in school & 8.737 & 1 & 8.737 & 6.112 & .016 \\
Pyramid power belief & 2.956 & 1 & 2.956 & 2.068 & .154 \\
Friends' beliefs & 3.574 & 1 & 3.574 & 2.500 & .118 \\
Error & 110.069 & 77 & 1.429 & &
\end{tabular}

C) Private Ratings

\begin{tabular}{lrrrrr} 
Source & \multicolumn{1}{c}{$S S$} & $d f$ & \multicolumn{1}{c}{ MS } & \multicolumn{1}{c}{$F$} & $p$ \\
\hline Condition $(1,5)$ & 2.486 & 1 & 2.486 & 0.199 & .657 \\
Year in school & 52.168 & 1 & 52.168 & 4.173 & .045 \\
Pyramid power belief & 95.247 & 1 & 95.247 & 7.618 & .007 \\
Friends' beliefs & 1.205 & 1 & 1.205 & 0.096 & .757 \\
Error & 1.205 & 77 & 12.502 & & \\
\hline
\end{tabular}

or time" - on his or her ability to influence the subject. Social impact theory predicts that immediacy heightens the impact of the confederate's judgments. We lowered immediacy by providing ratings from an ostensible prior subject, thus removed in both space and time from the subject's setting.

\section{Design}

In Condition 5, the experimenter read what he described as the ratings of a randomly selected subject who previously rated the same set of bananas. When compared to Condition 1, we may determine the relative effects of an absent confederate versus a confederate who is present in the room.

\section{Hypothesis}

Oral and private ratings should be influenced more in Condition 1 than in Condition 5 . 


\section{Results}

Panel A of Table 4 shows the relative effects of the absent confederate (Condition 5) and the proximate confederate (Condition 1). The predicted difference for these conditions was not observed (Table 4, Panel B). Ironically, this was because the impact of the absent confederate was unexpectedly strong. The effect relative to the no-confederate condition was borderline significant at $p=.054\left(\mathrm{~F}_{(1,59)}=\right.$ 3.873).

The analysis of the private ratings appears in Table 4, Panel C. Again, the basic hypothesis was not supported: The absent confederate had an unexpectedly strong impact-about the same impact on private ratings as the confederate who was present in the room with the subject.

\section{SUMMARY}

Overall, the results strongly support the claim that paranormal beliefs are transmitted by passive social influence in small groups. ${ }^{15}$ The contrast between Conditions 1 and 2 showed that a confederate exerts passive social influence on the expressed judgments of subjects, as predicted. The strength of this result lies in the mildness of the experimental manipulations: The lone confederate was equal in status to the subject, and the setting was noncoercive and nonpersuasive.

Contrasting "paranormal context" and "normal context" conditions (1 vs. 3) produced even more influence by removing paranormal connotations from the social setting. In terms of social impact theory, this suggests that the minimum possible number of influencers is sufficient to produce a robust impact, despite the damping effect of attaching paranormal overtones to the socially influenced judgments.

Contrasting "equal status" and "high status" conditions (1 vs. 4), we found enhanced influence due to the high-status confederate. The effect was not significant in private ratings, however. The contrast also revealed a surprising result: an absent confederate was nearly as influential as a proximate confederate. Although a clear case of social influence, it did not support social impact theory's "immediacy" prediction: the hypothesized decrement due to reduced immediacy was not significant.

\section{DISCUSSION}

Here we review several specific points that bear further consideration. In the section that follows we address some general issues informed by this project.

\section{Unsupported Hypotheses}

Explicit scope conditions and definitions of key theoretical concepts guide empirical tests and applications (Cohen 1989; Walker and Cohen 1985). Social impact theory lacks scope conditions and tends to employ broad and imprecise 
definitions for key terms such as strength and immediacy. The theory needs to be made more explicit. Short of this, we cannot know whether unsupported hypotheses are attributable to problems with procedures or measures. Although our tests point to the strong conclusion that social impact occurs in the realm of paranormal beliefs, some of the theory's claims must remain provisional.

For example, the high-status source did not heighten impact on private ratings significantly beyond the impact of the equal-status source. It may be that a stronger status manipulation with greater relevance to the paranormal claim is needed; or perhaps a "cleaner" measure of the current manipulation. Alternatively, status differences may not operate the same way as other strength factors. Their impact may be more specific to verbal responses in the interaction setting itself and less conducive to long-lasting belief change. In this respect, a distinction between informational influence and normative influence may be relevant (Deutsch and Gerard 1955; see note 5). That is, a university professor in our setting may have heightened impact relative to the equal-status confederate due to a perception that he exerts informational influence (e.g., subjects try to resolve the ambiguous judgment by referring to his ratings) and normative influence (e.g., subjects may perceive a threat of sanction for disagreeing with a professor). Then, in the private ratings phase, the professor's normative impact would recede, leaving only informational impact. Because of the loss of normative impact, we would expect a narrowing of the influence gap when the professor's influence is measured across public and private ratings, just as we observed. Our measures do not permit a direct test of this possibility, but our data are consistent with this inference. The immediacy hypothesis received the weakest support in that the absent confederate had more impact than expected-a level nearly equal to that of a confederate sitting across the table. There are several possible reasons for this result. First, the test may have lacked statistical power. It may be that with more refined influence measures and/or larger sample sizes, we would have found a significant decrement in the impact of the absent confederate. Second, the information delivered in the experimental setting may have provided an unnaturally vivid portrayal of the absent confederate's responses-almost as if the confederate actually were present. A third possibility is that the theory is wrong, or at least fails to account for whatever contingencies led to such high impact in this experiment.

\section{Anchor Effects}

Is it possible that the observed influence is asocial, attributable only to the information provided by the confederate? The anchoring literature suggests that the information alone would have been sufficient to bias our subjects' judgments by providing numerical referents toward which subjects' evaluations are assimilated (e.g., Hinsz and Indahl 1995; Markovsky 1988). However, our results suggest that social effects combined with the informational: by design, confederates in all of the experiments made identical judgments; therefore, differences in confederate conditions across experiments must have been due to variations in social factors, not to pure anchor effects. ${ }^{16}$ 


\section{Covariates}

Our experimental setting prevents the intrusion of many complicating factors, but we cannot hold constant our subjects' presuppositions and prior beliefs. The best that we can hope to do in this regard is impose experimental and statistical controls, capitalizing on random assignment procedures and parsing off variation in the dependent variables attributable to idiosyncratic factors. By including covariates in our statistical models, we allowed for the possibilities that (1) susceptibility to social influence declines with progress through college; (2) prior beliefs in the paranormal, and, more specifically, prior belief in pyramid power, increase susceptibility to influence; and (3) having friends who believe paranormal claims increases one's susceptibility to influence on paranormal issues.

That the first of these covariates proved significant is not very startling. However, we were surprised by the irrelevance of prior beliefs in paranormal phenomena and the insignificance of friends' beliefs for private ratings. Prior beliefs in the paranormal have been important factors in other research on paranormal or supernatural beliefs (e.g., Bainbridge 1978). However, our research suggests that people may express paranormal inclinations without internalizing them. In turn, social influence and diffusion-without the internalization of paranormal claimsmay play even greater roles in the dissemination of paranormal beliefs than we first imagined. It also suggests that, although scores on omnibus paranormal belief scales correlate with various personal traits and social ascriptions (e.g., Gallup and Newport 1990; Harrold and Eve 1987a; Tobacyk and Milford 1983), individual beliefs in particular claims may generalize only to very similar claims unless social influence factors happen to play a facilitating role. For instance, one who already believes in the claim that pyramids can preserve fruit may be more likely to accept the claim that pyramids have healing powers; and then that crystals also have healing powers; and then that certain people have supernormal healing powers; and so on. On the other hand, under the impact of numerous, proximate, and strong social ties, group members should be far more likely to leap to paranormal conclusions that are not associated with prior beliefs. Social impact at the interpersonal level can thus help to generate a culture of paranormality.

As for the lack of covariation between friends' beliefs in the paranormal and subjects' private judgments, we speculate that the social nature of the covariate could make it more effective under social conditions. The influence of the credulous confederate may create an implicit consensus with absent (but possibly salient) friends who also are believers. Clearly this is an area for further investigation.

\section{CONCLUSION}

Public opinion surveys indicate that the overwhelming majority of Americans believe some paranormal claims. At the same time, most specific beliefs are minority viewpoints. This may indicate low exposure rates to particular claims, but it seems unlikely given the high profile of so many paranormal claims and claimants. It is more likely that most people are cognizant of the marginal status of these claims but hesitant to accept them without social support. Our evidence suggests 
that such cautiousness results in a degree of resistance to social influence-not a high degree, necessarily, but enough to stave off beliefs in claims at the "wilder" end of the plausibility spectrum, at least until the needed social support is perceived to be in place. That support may originate in the strength, immediacy, or number of real or imagined reference groups, or in networks of significant others-family, friends, work colleagues, and so forth. Our findings also suggest that paranormal claims endorsed by proximal, legitimate, higher-status others are especially contagious.

As social theorists and researchers, our results are intriguing because they suggest that existing theories may be applicable to paranormal belief formation and maintenance. At the same time, there are nuances that may differentiate these beliefs and their determinants from other types of beliefs and influences. As educators, we also are intrigued by the year-in-college covariate: we actually may have an impact on college students' critical thinking ability-or at least in giving them the confidence to resist influence on the basis of others' flawed judgments. This can only help to stem the tide of a burgeoning paranormal industry that profits well from the sort of beliefs that we show can emerge solely from social processes, absent any physical evidence.

Acknowledgments: This research was supported by the Center for the Study of Group Processes at the University of Iowa. Jeff Erger and Shari Burggraf assisted with data collection. We are grateful for helpful comments on earlier versions that were provided by Judith Howard, Karen Heimer, Michael Lovaglia, Lisa Troyer and several anonymous reviewers.

\section{NOTES}

1. In surveys and popular accounts, readers usually are left to infer their own meanings for terms such as "paranormal," "supernatural," and "occult," although various definitions have been offered in the academic literature (Alcock 1990; Braude 1978; Truzzi 1971, 1987). In that literature, usually "supernatural" events are those presumed to be outside the purview of natural explanations, sometimes but not necessarily evoking religious connotations. "Occult" is more of an omnibus term used to subsume not only the supernatural but also astrology, witchcraft, spiritualism, and so on. "Paranormal" often receives a narrower definition that designates unexplained phenomena considered to be natural. Truzzi's terms "anomaly" and "scientific anomaly" best describe our interests. They subsume all of the above and more. For example, the Loch Ness monster would be an anomaly not because it necessarily violates any physical laws but because it is so unlikely in view of existing theoretical and empirical knowledge. Strictly speaking, then, our use of the term "paranormal beliefs" corresponds to its common usage, but to be precise it should be taken to mean "beliefs in anomalies."

2. Our focus is on beliefs in the types of claims that most scientific anomalies researchers would deem unfounded. For example, research by the first author (Markovsky 1997) finds that the majority of leading parapsychologists claim not to be convinced by the colorful bits of anecdotal evidence or demonstrations of ESP so prevalent in the popular culture. Conversely, the public is almost completely unaware of the experimental evidence for psychic phenomena that parapsychologists find compelling (e.g., Radin 
1997). Whereas widespread belief in unfounded and demonstrably false paranormal claims arguably is a social problem, we would not want to tar with this same brush the body of higher-quality research on scientific anomalies.

3. The social influence literature is not the only area of theory and research that bears on the present work. Paranormal beliefs are suspended in an intricate causal web of social forces and consequences. The psychologies of cognition, belief, and experience and the sociologies of culture, science, knowledge, and religion also have much to offer. For example, Kirkpatrick's (1997) study found qualified support for a relationship between attachment styles (e.g., commitment to relationships) and religiosity, the notion being that certain religious beliefs are tantamount to spiritual attachments that may compensate for the lack of certain social attachments. Yamane and Polzer (1994) focused on a more sociological aspect of religiosity: how religious traditions create alternative realities for adherents, which in turn facilitate ecstatic experiences with paranormal characteristics. MacDonald (1995) established an even stronger tie between religious and paranormal beliefs. He presented empirical support for a "cultural source" hypothesis not unlike Yamane and Polzer's; that is, one who holds religious beliefs is preconditioned to also hold paranormal beliefs and to have paranormal experiences. Underlying all such approaches, however, are implicit social influence assumptions. Our research focuses on those assumptions and the various dimensions along which influence operates.

4. The theory also assumes that social impact is negatively related to the strength, immediacy, and number of the targets, all of which we hold constant in the research presented here.

5. As one reviewer noted, the theory does not take into account Deutsch and Gerard's (1955) distinction between informational social influence and normative social influence. Social impact theory was designed to subsume such distinctions, in the sense that whether the basis for influence is normative, informational, or otherwise, the effects of its three main factors are assumed to hold true. We are not aware of any research that contradicts this contention.

6. We reasoned in advance that, even without positive results, the experiment would have pedagogical utility. In fact, planning the experiment proved very instructive, as we discovered numerous points at which the potential for information leakage and experimenter bias effects had to be controlled through imposing standard controls such as blinding and randomization. An unpublished report on the procedures and results is available from the authors on request.

7. Purveyors of pyramid power agree that only the pyramid's shape matters, not the material from which it is constructed. We used mat board (1/8" solid cardboard), and acknowledge the precision craftsmanship of Rose Garfinkle who built our pyramid and box.

8. One item ( $\# 12$; mean $=8.29$, $\mathrm{sd}=4.91, N=185)$ was included for exploratory purposes and was not intended to assess any paranormal belief.

9. Strictly speaking, Latané's (1981) social impact theory predicts two effects from increasing the number of sources: (1) that overall levels of social impact will increase with each additional source, but (2) increasing the number of sources has a diminishing marginal impact. Because we seek to establish the minimal necessary conditions for social impact, our experiments test only the first effect, that is, the impact of increasing from zero source to one source. However, the theory would predict even greater impact for increasing numbers of confederates.

10. A total of 199 subjects participated in the five conditions. A total of fourteen subjects (7\%) were excluded after postexperiment interviews revealed strong suspicions 
regarding experimental manipulations. Conditions had approximately equal numbers of males and females, and there were no gender effects in our analyses. The reason for the larger number of subjects in Condition 1 (and the subsequent confederate conditions) was that we anticipated that a bimodal distribution may emerge-the influenced and the noninfluenced. A larger number of subjects would therefore increase statistical power in post hoc tests. Although influence was clearly detectable (as noted below), its distribution across subjects is not obviously bimodal.

11. Based on findings from previous research (Kirkpatrick 1997; MacDonald 1995), one reviewer suggested sex, race, and stress as possible covariates. We found no significant effects of sex, and our sample was too homogeneous to conduct a meaningful test for race. We had no measure for stress; however, we note that random assignments of subjects to experimental conditions would prevent any systematic biasing effects due to covariates and only manifest as increased variability in the data. As for the lack of a significant effect for the paranormal beliefs subscale, this is not as surprising as it may first appear. Overall, previous investigations have not identified consistent patterns of correlations among paranormal beliefs.

12. Results without the covariates still indicated a significant, though weaker, confederate effect: $\mathrm{F}_{(1,62)}=4.611, p=.036$. We also found that dummy variable regression analyses yielded results very similar to those of the ANCOVA.

13. One reviewer thought that we should have used a between-subjects rather than within-subjects design to show confederate effects on private ratings. All else equal, however, a between-subjects test would be less powerful than our within-subjects design. Because each pair of measures comes from the same person in the withinsubjects approach, within-group variance is less than it would be for two distinct groups. The result is a better chance of detecting a small but real effect.

14. Dynamic social impact theory (Nowak, Szamrej, and Latané 1990) predicts that opinions converge over the course of successive interactions. Therefore, we also examined $\mathrm{D}$ ratings within subjects and across trials (aggregated across all conditions) to see whether they exhibited any such effects. There was no significant trend.

15. Although some of the individual contrasts on private ratings were not significant, combining the four confederate conditions provided a more powerful statistical test of the general prediction that confederates influence private ratings. The mean private rating scores were $.304(N=23 ; \mathrm{SD}=2.803)$ in Condition 2 , and $2.179(N=162 ; \mathrm{SD}=3.843)$ for the remaining conditions. This difference was highly significant in a planned comparison test: $\left.\mathrm{F}_{(1,177)}=9.015 ; p=.003\right)$.

16. The paranormal/normal context factor is not overtly social, but it did entail anchors identical to those in the other conditions and so provides further evidence against a pure anchoring effect and for a social impact effect.

\section{REFERENCES}

Alcock, James. 1980. Parapsychology: Science or Magic? A Psychological Perspective. Toronto: Pergamon.

- 1990. Science and Supernature: A Critical Appraisal of Parapsychology. Buffalo, NY: Prometheus.

Asch, Solomon. 1956. "Studies of Independence and Submission to Group Pressure: I. On Minority of One Against a Unanimous Majority." Psychological Monographs 70(9):1-70. Babbie, Earl. 1989. The Practice of Social Research. Belmont, CA: Wadsworth. 
Bainbridge, William Sims. 1978. "Chariots of the Gullible." Skeptical Inquirer 3(2):33-48.

Baker, Robert. 1992. Hidden Memories. Buffalo, NY: Prometheus.

Balkwell, James W. 1994. "Status." Pp. 119-48, Group Processes: Sociological Analyses, edited by Martha Foschi and Edward J. Lawler. Chicago: Nelson-Hall.

Barrett, Stephen and William T. Jarvis. 1993. The Health Robbers: A Close Look at Quackery in America. Buffalo, NY: Prometheus.

Blackmore, Susan. 1991. "Near-Death Experiences: In or Out of the Body?" Skeptical Inquirer 16(1):34-45.

___ 1993. Dying to Live: Near-Death Experiences. Buffalo, NY: Prometheus.

Blackmore, Susan and Tom Troscianko. 1985. "Belief in the Paranormal: Probability Judgments, Illusory Control, and the 'Chance Baseline Shift.'" British Journal of Psychology 76:459-68.

Braude, S. 1978. "On the Meaning of the 'Paranormal.'” Pp. 43-63 in Philosophy and Parapsychology, edited by J. Ludwig. Buffalo, NY: Prometheus.

Buckman, Robert and Karl Sabbagh. 1995. Magic and Medicine: An Investigation of Healing and Healers. Buffalo, NY: Prometheus.

Cazeau, C. 1986. Exploring the Unknown: Great Mysteries Reexamined. New York: Plenum.

Cohen, Bernard P. 1989. Developing Sociological Knowledge. Chicago: Nelson-Hall.

Daniels, Pat and Anne Horan, eds. 1987. Mystic Places. Alexandria, VA: Time-Life.

Davis, James A. and Tom W. Smith. 1991. General Social Surveys, 1972-1991. Chicago: National Opinion Research Center.

Dawkins, Richard. 1989. The Selfish Gene. New York: Oxford University Press.

Deutsch, Morton and H. Gerard. 1955. "A Study of Normative and Informational Social Influences upon Individual Judgment." Journal of Abnormal and Social Psychology 51:629-36.

Erickson, Bonnie H. 1988. "The Relational Basis of Attitudes." Pp. 99-121 in Social Structures: A Network Approach, edited by B. Wellman and S. D. Berkowitz. New York: Cambridge University Press.

Friedkin, Noah E. 1991. "Theoretical Foundations for Centrality Measures." American Journal of Sociology 96:1478-1504.

. 1993. "Structural Bases of Interpersonal Influence in Groups: A Longitudinal Case Study." American Sociological Review 58:861-72.

Friedlander, Michael W. 1995. At the Fringes of Science. Boulder, CO: Westview.

Gallup, George H. 1979. The Gallup Poll: Public Opinion, 1978. New York: Random House.

—_ 1997. The Gallup Poll: Public Opinion, 1996. Wilmington, DE: Scholarly Resources.

Gallup, George and F. Newport. 1990. "Belief in Psychic and Paranormal Phenomena Widespread among Americans." Gallup Poll Monthly 299 (August):35-44.

Gardner, Martin. 1957. Fads and Fallacies in the Name of Science. New York: Dover.

- 1991. The New Age: Notes of a Fringe Watcher. Buffalo, NY: Prometheus. 1992. On the Wild Side. Buffalo, NY: Prometheus.

Gilovich, Thomas. 1991. How We Know What Isn't So: The Fallibility of Human Reason in Everyday Life. New York: Free Press.

Goode, Erich. 2000. Paranormal Beliefs: A Sociological Introduction. Prospect Heights, IL: Waveland Press.

Gray, Thomas. 1985. "Changing Unsubstantiated Belief: Testing the Ignorance Hypothesis." Canadian Journal of Behavioral Science 17(3): 263-70.

Greeley, Andrew. 1975. Sociology of the Paranormal: A Reconnaissance. London: Sage.

Harrold, Francis B., and Raymond A. Eve, eds. 1987a. Cult Archaeology and Creationism. Iowa City: University of Iowa Press.

1987b. "Patterns of Creationist Beliefs among College Students." Pp. 68-90 in Cult 
Archaeology and Creationism, edited by Francis B. Harrold and Raymond A. Eve. Iowa City: University of Iowa Press.

Hassan, Steven. 1988. Combatting Cult Mind Control. Rochester, VT: Park Street Press.

Hinsz, Verlin B. and Kristin E. Indahl. 1995. "Assimilation to Anchors for Damage Awards in a Mock Civil Trial." Journal of Applied Social Psychology 25(11):991-1026.

Huber, Peter W. 1991. Galileo's Revenge: Junk Science in the Courtroom. New York: Basic Books.

Kirkpatrick, Lee A. 1997. “A Longitudinal Study of Changes in Religious Belief and Behavior as a Function of Individual Differences in Adult Attachment Style." Journal for the Scientific Study of Religion 36:207-17.

Klare, Roger. 1990. "Ghosts Make News: How Four Newspapers Report Psychic Phenomena." Skeptical Inquirer 14:363-71.

Kurtz, Paul. 1991. The Transcendental Temptation. Buffalo, NY: Prometheus.

Latané, Bibb. 1981. "The Psychology of Social Impact." American Psychologist 36:343-56.

Latané, Bibb and Todd L'Herrou. 1996. "Spatial Clustering in the Conformity Game: Dynamic Social Impact in Electronic Groups." Journal of Personality and Social Psychology 70(6):1218-30.

Latané, Bibb, James H. Liu, Andrzej Nowak, and Michael Bonevento. 1995. "Distance Matters: Physical Space and Social Impact." Personality and Social Psychology Bulletin 21(8):795-805.

Latané, Bibb and Sharon Wolf. 1981. "The Social Impact of Majorities and Minorities." Psychological Review 88:438-53.

MacDonald, William L. 1994. "The Popularity of Paranormal Experiences in the United States." Journal of American Culture 17(3):35-42.

. 1995. "The Effects of Religiosity and Structural Strain on Reported Paranormal Experiences." Journal for the Scientific Study of Religion 34:366-76.

Markovsky, Barry. 1988. "Anchoring justice." Social Psychology Quarterly 51:213-24.

McAneny, Leslie. 1995. "It Was a Very Bad Year: Belief in Hell and the Devil on the Rise." Gallup Poll Monthly 304 (January):14-17.

McClenon, James. 1994. Wondrous Events. Philadelphia: University of Pennsylvania Press.

Miller, Russell. 1987. Bare-faced Messiah: The True Story of L. Ron Hubbard. London: M. Joseph. Available at http:/ / www.cs.cmu.edu/ dst/Library/Shelf/bfm/bfmconte.htm.

Nisbett, Richard E. and Lee Ross. 1980. Human Inference: Strategies and Shortcomings of Social Judgment. Englewood Cliffs, NJ: Prentice-Hall.

Nollinger, Mark. 1994. "Something Weird Is Coming to a TV Near You." TV Guide, October 22, pp. 16-20.

Nowak, A., J. Szamrej, and B. Latané. 1990. “From Private Attitude to Public Opinion: A Dynamic Theory of Social Impact." Psychological Review 97:362-76.

Nowak, Andrzej and Robin R. Vallacher. 1998. Dynamical Social Psychology. New York: Guilford Press.

O'Keefe, Daniel J. 1990. Persuasion: Theory and Research. Newbury Park, CA : Sage.

Ostrander, Sheila and Lynn Schroeder. 1970. Psychic Discoveries behind the Iron Curtain. Englewood Cliffs, NJ: Prentice-Hall.

Otis, Laura P. and James E. Alcock. 1982. "Factors Affecting Extraordinary Belief." Journal of Social Psychology 118:77-85.

Paulos, John Allen. 1988. Innumeracy. New York: Hill and Wang.

-_. 1991. Beyond Innumeracy. New York: Knopf.

Petty, Richard T. and John T. Cacioppo. 1986. Communication and Persuasion: Central and Peripheral Routes to Attitude Change. New York: Springer-Verlag.

Pratkanis, Anthony. 1995. "How to Sell a Pseudoscience." Skeptical Inquirer 19(4):19-25. 
Pratkanis, Anthony and Elliot Aronson. 1992. Age of Propaganda: The Everyday Use and Abuse of Persuasion. New York: W. H. Freeman.

Radin, Dean. 1997. The Conscious Universe: The Scientific Truth of Psychic Phenomena. New York: HarperCollins.

Randi, James. 1987. The Faith Healers. Buffalo, NY: Prometheus.

Reed, Graham F. 1988. The Psychology of Anomalous Experience: A Cognitive Approach. Buffalo, NY: Prometheus.

Rogers, Everett M. 1983. Diffusion of Innovations. (3d ed.). New York: Free Press.

Sagan, Carl. 1995. The Demon-Haunted World. New York: Random House.

Sherif, Muzafer. 1935. "A Study of Some Social Factors in Perception." Archives of Psychology 27(187):1-60.

Shermer, Michael. 1997. Why People Believe Weird Things. New York: W. H. Freeman.

Singer, Margaret Thaler. 1995. Cults in Our Midst. San Francisco: Jossey-Bass.

Spanos, Nicholas P. 1996. Multiple Identities and False Memories: A Sociocognitive Perspective. Washington, DC: American Psychological Association.

Sparks, Glenn G. 1998. "Paranormal Depictions in the Media: How Do They Affect What People Believe?" Skeptical Inquirer 22(4):35-39.

Sparks, Glenn G. and M. Pellechia. 1997. "The Effect of News Stories about UFOs on Readers' UFO Beliefs: The Role of Confirming or Disconfirming Testimony from a Scientist." Communication Reports 10:165-72.

Sparks, Glenn G., C. L. Nelson, and R. G. Campbell. 1997. "The Relationship between Exposure to Televised Messages about Paranormal Phenomena and Paranormal Beliefs." Journal of Broadcasting and Electronic Media 41:345-59.

Sparks, Glenn G., C. W. Sparks, and K. Gray. 1995. "Media Impact on Fright Reactions and Belief in UFOs: The Potential Role of Mental Imagery." Communication Research 22:323.

Stenger, Victor J. 1990. Physics and Psychics: The Search for a World beyond the Senses. Buffalo, NY: Prometheus.

Stine, G. Harry. 1992. Mind Machines You Can Build. Largo, FL: Top of the Mountain Publishing.

Thye, Shane and B. Markovsky. 1994. "Social Influence on the Acceptance of Normal and Paranormal Claims." Paper presented at the Annual Meetings of the American Sociological Association, Los Angeles.

Tobacyk, Jerome and Gary Milford. 1983. "Belief in Paranormal Phenomena: Assessment Instrument Development and Implications for Personality Functioning." Journal of Personality and Social Psychology 44:1029-37.

Tobacyk, Jerome, Mark J. Miller, Patsy Murphy, and Thomas Mitchell. 1988. "Comparisons of Paranormal Beliefs of Black and White University Students from the Southern United States." Psychological Reports 63(2):492-94.

Toth, Max. 1974. Pyramid Power. New York: Destiny Books.

Truzzi, Marcello. 1971. "Definition and Dimensions of the Occult: Towards a Sociological Perspective." Journal of Popular Culture 3: 635-46.

. 1987. "Zetetic Ruminations on Skepticism and Anomalies in Science." Zetetic Scholar 12-13:7-20.

Vyse, Stuart A. 1997. Believing in Magic: The Psychology of Superstition. New York: Oxford University Press.

Wagner, David G. and Joseph Berger. 1993. "Status Characteristics Theory: The Growth of a Program." Pp. 23-63 in Theoretical Research Programs: Studies in the Growth of Theory, edited by Joseph Berger and Morris Zelditch, Jr. Stanford, CA: Stanford University Press. 
Walker, Henry A. and Bernard P. Cohen. 1985. "Scope Conditions: Imperatives for Sociological Theory." American Sociological Review 50:288-301.

Watson, Lyall. 1973. Supernature. Garden City, NY: Anchor Press.

Wierzbicki, Michael. 1985. "Reasoning Errors and Belief in the Paranormal." Journal of Social Psychology 125(4):489-94.

Woodward, Bob. 1996. The Choice. New York: Simon and Schuster.

Yamane, David and Megan Polzer. 1994. "Ways of Seeing Ecstasy in Modern Society: Experimental-Expressive and Cultural-Linguistic Views." Sociology of Religion 55:1-25.

Zusne, L. and W. Jones. 1982. Anomalistic Psychology: A Study of Extraordinary Phenomena of Behavior and Experience. Hillsdale, NJ: Lawrence Erlbaum Associates. 


\section{APPENDIX: QUESTIONNAIRES}

\section{Part 1: Background Information and Paranormal Beliefs Form}

1) Age

2) Year in college $1 \quad 2 \quad 3 \quad 3 \quad 4 \quad 5 \quad 6$

3) Academic Major

a) Social/Behavioral Sciences (Sociology, Psychology, Anthropology, Political Science, Social Work, etc.)

b) Humanities (Art, English, Languages, Philosophy, History, Music, Journalism, Communications, etc.)

c) Engineering, Computer Science

d) Education

e) Natural/Physical Sciences (Biology, Chemistry, Geology, Physics, Mathematics, Pre-med., Medicine, Nursing, Pharmacy, etc.]

f) Business (Accounting, Management, Finance, etc.)

g) Other

4) Sex $M$ F

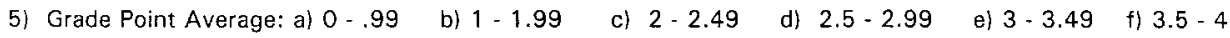

\section{Part II: Paranormal Beliefs}

\section{Instructions}

Fill in the blank next to each statement with the number that best describes your beliefs about the statement. The range is:

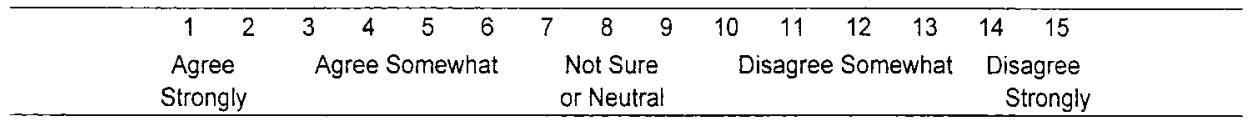

1. _. Some people can predict future events using psychic powers (ESP).

2. Reincarnation really exists.

3. Aliens from other worlds are responsible for ancient monuments like the pyramids -- objects that primitive people could not have built.

4. The Loch Ness Monster exists only in the imagination.

5. Astrological charts can predict certain personality characteristics.

6. U.F.O.s are actual spacecraft from other planets.

7. Black magic really exists.

8. A curse on the tomb of the Egyptian pharaoh King Tut actually killed people attempting to pillage the tomb.

9. Our government is hiding information about the fact that U.F.O.s are alien spacecraft.

10. One cannot read other people's thoughts by psychic powers.

11. Miracles that violate natural laws have never occurred.

12. I I have heard claims that pyramids have special powers to physically affect objects kept within them (for example, keep fruit fresh and razor blades sharp).

13. _._ I believe claims that pyramids have special powers to physically affect objects kept within them.

14. _ Some of my best friends believe in ESP

15. _ Some of my best friends believe in Astrology.

16. Some of my best friends believe in reincarnation.

17. Some of my best friends believe that U.F.O.s are alien spacecraft.

18. Some of my best friends believe in Black Magic.

19. Some of my best friends believe in miracles that violate natural laws.

20. Some of my best friends believe in pyramid power. 